\title{
Characterization of sedimentary humic matter by alkaline hydrolysis
}

\author{
Richard A. BourbonNIERE \\ National Water Research Institute, Canada Centre for Inland Waters, P.O. Box 5050, Burlington, \\ Ontario, Canada L7R 4A6 \\ and \\ PHILIP A. MEYers \\ Oceanography Program, Department of Atmospheric and Oceanic Science, The University of Michigan \\ Ann Arbor, MI 48109, U.S.A.
}

(Received 7 April 1983; accepted 16 August 1983)

\begin{abstract}
Humic matter fractions from modern sediments of Lake Huron and Lake Michigan have been compared. Large yields of saccharinic acids from alkaline hydrolysis suggest that these fractions contain large portions of carbohydrate materials. Evidence for contributions of aquatic lipid (C-16 fatty acids) and of liginin (phenolic acids) to these sediments is also present in the hydrolysis products. Qualitative differences among fulvic acid, humic acid and humin from the same lake are minor, suggesting common (or similar) organic sources for these fractions. The lability of sedimentary humic matter to alkaline hydrolysis is inversely related to its degree of exposure to oxidative weathering. Lability may also be related to diagenetic state as fulvic acids generally yield greater quantities of hydrolysis components than humic acids which in turn yield more than humin.
\end{abstract}

\section{INTRODUCTION}

Humic matter comprises the bulk of organic matter in natural systems. Although much research effort has gone into the study of soil humic matter, comparatively few studies have focused on sedimentary humic materials. Among these, elemental and spectroscopic characteristics of the humic materials isolated from freshwater sediments have been reported (Otsuki and Hanya, 1967; Ishiwatari, 1970, 1973; Kemp, 1973; Kemp and Mudrochova, 1973). In general, these studies have shown that sedimentary humic matter is composed of material of both aquatic and terrestrial origin. Recent studies of humic matter of various origin by NMR spectroscopy have shown varying proportions of aliphatic and aromatic structures (Stuermer and Payne, 1976; Hatcher et al., 1980a,b; Dereppe et al., 1980; Hatcher, et al., 1981a,b; Wershaw et al., 1981).

Chemical degradation has been used to characterize soil humic matter (Schnitzer and Khan, 1972) and has also been applied to freshwater studies. Ishiwatari (1975) oxidized humic acid from Lake Haruna sediment with alkaline $\mathrm{KMnO}_{4}$ and released a variety of aliphatic and aromatic acids. Kemp and Mudrochova (1973) studied amino acids released by acid hydrolysis of fulvic and humic acids from a Lake Ontario sediment sample. Alkaline hydrolysis has been used successfully on soil humic matter by Jakab et al. (1963), Neyroud and Schnitzer (1975) and Tsutsuki and Kuwatsuka (1979).

Here we report chemical characteristics of humic matter from modern sediments of Lakes Huron and
Michigan. The focus of this paper is on products released by alkaline hydroiysis of humic matter fractions. These are compared to hydrolysis products from a number of locally derived materials which are potential sources of, or precursors to, the sedimentary humic matter.

\section{EXPERIMENTAL}

\section{Sediment samples}

The sediment samples analyzed were obtained with a $6.7 \mathrm{~cm}$ I.D. Benthos ${ }^{\text {n: }}$ gravity corer. Physical disturbance during the coring operation was minimized by using a butterfly type valve and leaving the penetration end open, without a core catcher. Cores were extruded vertically and sectioned within one hour after collection, frozen immediately and stored at $-20^{\circ} \mathrm{C}$ in glass containers until analysis. One core, designated SLH75-18, was taken in the Goderich Basin of southern Lake Huron $\left(44^{\circ} 00^{\prime} \mathrm{N}\right.$., $81^{\circ} 59^{\prime} \mathrm{W}$; water depth $63 \mathrm{~m}$ ) in September, 1975. The other core designated SLM77-26, came from southeastern Lake Michigan $\left(42^{\circ} 20^{\prime} \mathrm{N} ., 86^{\circ} 50^{\prime} \mathrm{W}\right.$.; water depth $\left.118 \mathrm{~m}\right)$ and was collected in July, 1977.

The Lake Huron site is characterized by a present-day sedimentation rate of $0.11 \pm 0.01 \mathrm{~cm} / \mathrm{yr}$. This was determined by ${ }^{210} \mathrm{~Pb}$ geochronology measured on a companion core by Robbins et al. (1977) at their station 18. Vertical mixing caused mostly by bioturbation extends to a depth of $3 \mathrm{~cm}$ at this location (Robbins et al., 1977; Krezoski et al. 1978). The present day sedimentation rate at the Lake Michigan site is $0.10 \mathrm{~cm} / \mathrm{yr}$ (Edgington and Robbins, 1975 , their station 26). This was determined from ${ }^{137} \mathrm{Cs}$ data as was the vertical mixing depth of $2 \mathrm{~cm}$

Fractionation of humic matter and chemical analyses were done on $1 \mathrm{~cm}$ sections for the upper parts of both cores. For the purposes of this report, data for the top $4 \mathrm{~cm}$ of each core were combined and weighed according to the proportion that the dry sediment weight of each $1 \mathrm{~cm}$ section is to the total dry weight of the $0-4 \mathrm{~cm}$ interval. 
These combined data therefore represent material deposited during about the last 50 years at both sites.

\section{Ancillary samples}

The diatom Asterionella formosa and the green alga Chlamydomonas sp. were cultured on sterilized "WC medium" (Guillard, 1975). The bacterium Escherichia coli was grown on Difco Nutrient Broth. After sufficient growth had taken place, the cultures were centrifuged for $2 \mathrm{hr}$ at $4000 \mathrm{~g}$, washed twice with sterile $0.85 \% \mathrm{NaCl}$ to remove traces of media and freeze-dried.

A sample of white spruce wood (Picea glauca) from a forest buried by glacial outwash 10,000 years ago (Hughes and Merry, 1978) was freeze-dried, ground and homogenized. This sample is designated "Pleistocene spruce". For comparison, a piece of freshly cut white spruce was prepared in the same way and designated "modern spruce" (Meyers et al., 1980b). A piece of celery (Apium graveolens) was used as a source of crude cellulose for comparative purposes.

A topsoil sample was obtained from an eroding bank on the eastern shore of southern Lake Michigan $\left(42^{\circ} 26.1^{\prime} \mathrm{N}\right.$., $86^{\circ} 15.8^{\prime} \mathrm{W}$.). A sample of glacial till was taken from a lower sedimentary layer on this same bluff. Further details on these soil samples are discussed by Bourbonniere (1979), where they are named LMS-4 and LMS-1, respectively. The soils were freeze-dried, ground and homogenized before use.

Glaciolacustrine clay was sampled from the lower part of a core taken from another site in southern Lake Huron $\left(43^{\circ} 50^{\prime}\right.$ N., $82^{\circ} 00^{\prime}$ W.) (Meyers et al., 1980a). This material underlies much of the post-glacial mud in Lake Huron and outcrops in several areas. Thomas et al. (1973) interpret glaciolacustrine clays as deep-water deposits of main and post-Algonquin glacial lakes, and as such were deposited about $10,000-11,000$ years before the present. These authors also suggest that the extremely fine grain size, deficiency in organic carbon, and high quartz content of this clay is consistent with a rock flour origin. The profile of inorganic carbon at this location indicates a high sedimentation rate consistent with periglacial conditions (Iwasiuk et al., 1977).

\section{Fractionation of organic matter}

The scheme in Fig. 1 constitutes the operational definitions of fulvic acid (FA), humic acid (HA) and humin (HU) as used most often by soil scientists (Schnitzer and Khan, 1972). In this study no attempt was made to isolate the $\mathrm{HU}$ fraction from the mineral phase, and this is thus the non-extractable or residual organic matter. FA is that fraction of the alkaline extract which remains soluble at low $\mathrm{pH}$. Note that according to these operational definitions, the sum of the fractions constitutes the total organic matter.

FA is soluble in methanol (Griffith and Schnitzer, 1975), and this property is utilized in separating it $(89-90 \%$ recovery) from the large quantities of $\mathrm{NaCl}$ which result from concentration of the FA solution. The FA's isolated in this way from these sediments are yellow to light brown fine powders which contain large quantities of ash, probably Si and $\mathrm{Al}$ hydroxides. HA appears as a brown colloid in low $\mathrm{pH}$ solution. It flocculates after standing several hours and is removed by centrifugation $(4000 \mathrm{~g})$. The HA precipitate is purified by repeated dissolution and precipitation, thus removing fine clay mineral contaminates. Purified and freeze-dried HA's from these sediments are dark brown to black granular solids with low ash contents.

\section{Elemental analyses}

Carbon and nitrogen data reported here were determined on a Hewlett-Packard Model 185-B CHN Analyser using cystine (N.B.S.) as a calibration standard. Total organic carbon (TOC) was determined on sediment samples treated with $1 \mathrm{~N} \mathrm{HCl}$ to remove carbonates. Standard deviations of atomic $\mathrm{N} / \mathrm{C}$ ratios ranged from 3 to $7 \%$ of the sample means for humic matter fractions.

\section{Alkaline hydrolysis}

The apparent selectivity towards breaking $\mathrm{C}-\mathrm{O}$ bonds and relative inefficiency for breaking $\mathrm{C}-\mathrm{C}$ bonds were reasons for selecting this degradation method. The successful use of alkaline hydrolysis by Jakab et al. (1963) and Neyroud and Schnitzer (1975) on soil humic matter prompted our adaptation of their procedures to a microscale level. FA, HA and HU fractions were hydrolyzed for the SLH75-18 and SLM77-26 sediment samples. The ancillary samples were hydrolyzed as whole, unfractionated samples.

Samples to be hydrolyzed were placed in $(10 \mathrm{ml})$ stainless steel reaction tubes. After addition of internal standard, (dodecanoic or heptadecanoic acid), nitrogen-purged $5 \mathrm{~N}$ $\mathrm{NaOH}$ was added and the tube sealed. Reaction tubes were placed in a steel pressure vessel half-filled with water. The hydrolysis proceeded for $12 \mathrm{hr}$ at $170^{\circ} \mathrm{C}$.

After cooling, the basic solution in the tubes was acidified with $6 \mathrm{~N} \mathrm{HCl}$, and the hydrolysis products were extracted from the acid solution with ethyl acetate. The extract was dried over anhydrous sodium sulfate and evaporated to dryness under vacuum at $30^{\circ} \mathrm{C}$.

\section{Gas-liquid chromatography}

The dry extracts were silylated at $125-130^{\circ} \mathrm{C}$ for $45 \mathrm{~min}$ with $100 \mu \mathrm{l}$ of BSFTA (Pierce Chemical Co.) prior to analysis on a Hewlett-Packard Model 5710 gas chromatograph coupled with an HP Model 3380A Integrating Recorder. The primary column used was $3 \mathrm{~m} \times 1 / 8$ in. (3.1 mm) o.d. stainless steel packed with $10 \% \mathrm{SP} 2250(50 \%$ methyl, 50\% phenyl silicone, Supelco Inc.) on 100/120 mesh Supelcoport temperature-programmed from 110 to $300^{\circ} \mathrm{C}$ at $4^{\circ} \mathrm{C} / \mathrm{min}$ with a final hold at $300^{\circ} \mathrm{C}$.

Chromatographic peaks were tentatively identified by comparing their retention indices on SP2250 to those of authentic standards. TMS esters of $n$-alkanoic acids (C5:0-C24:0) were used as a reference series for calculating retention indices after Kovats (1965). Standards and selected samples were also analyzed on a packed $10 \%$ SP2 100 ( $100 \%$ methyl silicone) column programmed from 80 to $270^{\circ} \mathrm{C}$ at $4^{\circ} \mathrm{C} / \mathrm{min}$ and a $30 \mathrm{~m} \times 0.25 \mathrm{~mm}$ i.d. glass capillary column coated with SP2250 programmed from 75 to $250^{\circ} \mathrm{C}$ at $4^{\circ} \mathrm{C} / \mathrm{min}$. Further confirmation was achieved by capillary GC-MS of selected samples on a Finnigan 1015 Quadrupole system. A $21 \mathrm{~m} \times 0.32 \mathrm{~mm}$ i.d. glass capillary coated with SE52 was used in the GC-MS work. It should be noted that the packed columns used in this study produced essentially the same chromatograms, with these samples, as were produced by the capillary columns.

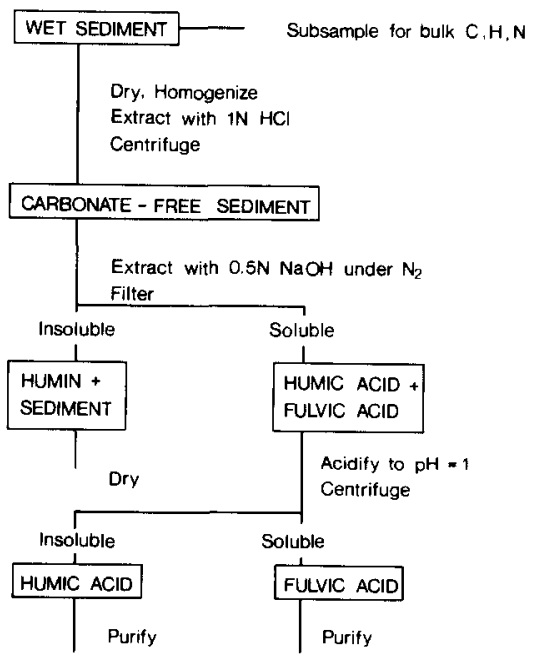

Fig. 1. Humic matter extraction and fractionation scheme. 
Quantification was achieved by comparing peak areas to those of internal standards on packed column SP2250 chromatograms. Differences in FID response factor relative to that of the internal standard were determined on quantitative mixtures of authentic standards. Corrections reflecting these differences were applied to all data.

All organic solvents used were ACS reagent grade redistilled in glass. Any solvent used as a reagent in sample workup was certified free of contaminants by GLC. All water used was deionized, glass-distilled and glass-distilled a second time from alkaline $\mathrm{KMnO}_{4}$ solution. All reagents were ACS reagent grade. Concentrated stock solutions were extracted with GLC certified dichloromethane and diluted to working concentrations with $\mathrm{KMnO}_{4}$-distilled water. Solid reagents were washed with appropriate GLC certified organic solvents and oven-dried.

\section{RESULTS AND DISCUSSION}

\section{Character of bulk organic matter}

Sediments from both Lake Huron and Lake Michigan contain c. $2.45 \%$ organic carbon (Table 1), which is typical of surficial sediments in the Goderich Basin of Lake Huron (Thomas et al., 1973) and in southeastern Lake Michigan (Shimp et al., 1971). The major part of the organic matter in these sediments is composed of the non-extractable HU fraction. FA is a lesser, and HA a minor proportion of the total organic matter (Table 1).
Atomic $\mathrm{N} / \mathrm{C}$ ratios of sedimentary humic matter and of ancillary samples (Table 2) suggest some differences in origin among sedimentary humic matter fractions. Values for the HU fraction of both sediments are nearer to those for topsoil, glaciolacustrine clay, celery and values reported for soil HU. Organic matter in the HU fraction of these sediments may be derived largely from eroded terrestrial material, and may contain insoluble plant tissue fragments which are low in nitrogen, e.g., white spruce, Table 2. Sedimentary HU may also contain organic matter of aquatic origin which has lost nitrogen prior to sedimentation.

Both sedimentary HA fractions and FA from SLM77-26 show N/C ratios like those of phytoplankton and are much higher than those typical of soil FA and HA (Table 2). The ratio for FA from SLH75-18 is even higher and is more like that of zooplankton and bacteria. A number of authors (Otsuki and Hanya, 1967; Ishiwatari, 1970; Nissenbaum and Kaplan, 1972; Kemp, 1973; among others) have suggested that sedimentary FA and HA are derived primarily from aquatic sources. Our N/C results agree with this suggestion.

\section{Composition of alkaline hydrolyzates}

Hydrolyzates of the humic matter fractions and the ancillary samples yielded $30-50$ GLC peaks. Thirteen

Table 1. Organic carbon distribution in sediment samples

\begin{tabular}{lcc}
\hline & SLH75-18 & SLM77-26 \\
\hline TOC (\% dry sediment) & 2.46 & 2.44 \\
OC distribution (\% of TOC) & 24.4 & 31.4 \\
Fulvic acid & 1.3 & 1.8 \\
Humic acid & 74.3 & 66.8 \\
Humin & & \\
\hline
\end{tabular}

Table 2. Atomic $\mathrm{N} / \mathrm{C}$ ratios of sedimentary humic matter and related materials ${ }^{a}$

\begin{tabular}{llc}
\hline SLH75-18: & Fulvic acid & 0.209 \\
& Humic acid & 0.111 \\
SLM77-26: & Humin & 0.087 \\
& Fulvic acid & 0.137 \\
& Humic acid & 0.132 \\
Soil humic matter ${ }^{b}$ : & Humin & 0.073 \\
& Fulvic acid & $0.012-0.056$ \\
Topsoil, Lake Michigan shore & Humic acid & $0.024-0.062$ \\
Till, Lake Michigan shore & Humin & $0.071-0.078$ \\
Glaciolacustrine clay, Lake Huron & & 0.063 \\
White spruce, modern & & $-f$ \\
White spruce, Pleistocene & & 0.073 \\
Celery (Apium graveolens) & & 0.022 \\
Phytoplankton: & & 0.049 \\
& & 0.062 \\
& A. formosa & 0.116 \\
& Chlamydomonas sp. & 0.133 \\
Zooplankton: & Scenedesmus sp ${ }^{c}$ & 0.152 \\
Bacteria: & Marine diatoms & \\
& Copepods, Lake Ontario ${ }^{e}$ & 0.115 \\
& Copepods, Marine & 0.197 \\
\hline
\end{tabular}

${ }^{a}$ This work unless otherwise noted.

${ }^{b}$ Schnitzer and Khan (1972)

Otsuki and Hanya (1967).

${ }^{d}$ Cited by Bordovskiy (1965)

${ }^{e}$ Kemp (1973)

No organic $\mathrm{N}$ found. 
Table 3. Selected components isolated by alkaline hydrolysis ${ }^{\alpha}$

\begin{tabular}{crl}
\hline Key $^{h}$ & $\begin{array}{c}\text { Retention } \\
\text { index }\end{array}$ & \multicolumn{1}{c}{$\begin{array}{c}\text { Tentative } \\
\text { Identification }\end{array}$} \\
\hline 1 & 572 & Lactic acid \\
2 & 604 & Oxalic acid \\
3 & 629 & 2-hydroxybutanoic acid \\
4 & 884 & Succinic acid \\
5 & 908 & Maleic/fumaric acids \\
6 & 1031 & 3,4-dihydroxybutanoic acid \\
7 & 1127 & 2-hydroxybenzoic acid \\
$\mathrm{X}$ & 1158 & Compound $X$ \\
8 & 1229 & 4-hydroxybenzoic acid \\
9 & 1270 & 2,5-dihydroxy-3-pentenoic acid \\
10 & 1409 & Vanillic acid \\
11 & 1600 & $n$-C16 fatty acids \\
12 & 1768 & Ferulic acid \\
13 & 1800 & $n$-C18 fatty acids \\
\hline
\end{tabular}

${ }^{a}$ For complete information on identification criteria, refer to Bourbonniere (1979).

${ }^{b}$ For reference to figures

Relative to $n$-alkanoic acid TMS esters.

of these peaks (Table 3) were chosen for closer study on the basis of: (1) their frequency of occurrence in the samples; (2) the amount of information available for their identification; (3) their generally high relative abundance in the hydrolyzates.

Aliphatic hydroxy acids. The four aliphatic hydroxy acids identified in the hydrolyzates of the humic matter fractions and of the ancillary samples are lactic acid, 2-hydroxybutanoic acid, 3,4-dihydroxybutanoic acid and 2,5-dihydroxy-3-pentenoic acid. These acids belong to a group of so-called saccharinic acids (Sowden, 1957), and are found frequently in liquors from the kraft paper process, which is an aqueous alkaline degradation of wood chips (Malinen and Sjostrom, 1975; Lowendahl et al., 1976).

Wood chemists have studied extensively the alkaline degradation of cellulose and related materials. Lowendahl et al. (1976) isolated lactic, 2-hydroxybutanoic and 3,4-dihydroxybutanoic acids in a 40:3:1 mass ratio from pine kraft black liquor among 25 hydroxy acids. Samuelson and Stolpe (1973) noted that lactic acid is the major component isolated when the process is carried out in the absence of oxygen. These results are significant because in the present study alkaline hydrolysis is accomplished in the absence of oxygen, and lactic acid is commonly a major component of hydrolysates. Isolation of 2,5-dihydroxy-3-pentenoic acid from alkaline oxidations of carbohydrates has not been reported. However 3,4-unsaturated compounds are postulated as intermediates in these reactions (Sowden, 1957).

Lactic and 2-hydroxybutanoic acids also may arise from microbial sources. Lactic acid is a common end product of glucose fermentation in many microorganisms, and lactic acid bacteria live in association with plants and decomposing plant tissues (Stanier et al., 1970). Nuti et al. (1975) reported appreciable concentrations of 2-hydroxybutanoic acid in several genera of soil microfungi.

An unidentified compound $(X)$ is a major component of the hydrolysates of the topsoil and glaciolacustrine clay samples GC-MS data suggest that this component is an unsaturated hydroxy acid. Arguments to support this are similar to those used to identify 2,5-dihydroxy-3-pentenoic acid (Bourbonniere, 1979, Appendix C).

Aliphatic dicarboxylic acids. The three aliphatic dicarboxylic acids identified in the alkaline hydrolyzates were oxalic acid, succinic acid, and maleic/fumaric acids.

Oxalic and succinic acids were found among the alkaline oxidation products of cellobiose (Lowendahl et al., 1975) and of pine chips (Lowendahl et al., 1976), usually at concentrations an order of magnitude lower than those of aliphatic hydroxy acids.

Oxalic acid constitutes a large portion of the dry weight of certain leaves, and is typically produced by fungi (Stevenson, 1967; Briggs et al., 1975). Wooddestroying fungi of the genera Formitopsis and Coriolus produce a considerable quantity of this acid (Milova, 1973). The fungus Aspergillus niger has been shown to produce oxalic acid from citric acid by a pathway involving the tricarboxylic acid cycle (Muller, 1975; Muller and Frosch, 1975).

Succinic acid is commonly found in all types of plants including the fungi. It is an intermediate in the tricarboxylic acid cycle (Stevenson, 1967; Stanier et al., 1970), and is one of the products of fermentation of glucose by a number of bacteria which are referred to as "mixed-acid fermenters" (Stanier et al., 1970). Maleic and fumaric acids are not resolvable by the chromatographic system used in this study. Fumaric acid is an intermediate in the tricarboxylic acid cycle (Stanier et al., 1970).

Aromatic acids. The four aromatic acids isolated and identified in alkaline hydrolyzates are 2-hydroxybenzoic acid, 4-hydroxybenzoic acid, vanillic acid, and ferulic acid. Vanillic, 4-hydroxybenzoic and ferulic acids are typical of the degradation products related to the lignin of vascular plants. Numerous studies have focused on the incorporation of ligninderived materials into humic matter (cf. Schnitzer and Kahn, 1972).

4-Hydroxybenzoic acid can be derived from the degradation of $p$-coumaric acid or related compounds by microbial processes or by chemical oxidation. It is indicative of the lignin of lower vascular plants (monocotyledons) because it does not occur in appreciable abundance in the lignins of conifers or hardwoods (Brown, 1964; Schubert, 1945; Flaig et al., 1975).

Vanillic acid is a more reliable indicator of vascular plant lignin. Precursors to vanillic acid are the only type that occur in conifer lignin; they are also found in appreciable quantities in hardwood lignin, as well as in monocotyledon lignin (Schubert, 1965; Flaig et al., 1975; Hedges and Parker, 1976). Thus vanillic acid is a general lignin indicator, and is not an indicator of a specific type of lignin.

Syringic acid was not detected in the hydrolyzates from this study; precursors so it are found only in hardwood and monocotyledon lignin (Schubert, 
1965; Flaig et al., 1975; Hedges and Parker, 1976). Its absence may indicate that these lignins are not significant sources in these sediments, or simply that syringic acid is generally a minor constituent of lignin relative to vanillic acid.

Ferulic acid is widespread in the plant kingdom, and can be considered as a non-specific indicator of plant sources to the sediments (Robinson, 1963). It is a derivative of coniferyl alcohol, a common lignin component, and can be converted to vanillic acid by $\beta$-oxidation (Towers, 1964; Schubert, 1965). Hedges and Parker (1976) found ferulic acid in the alkaline cupric oxide oxidation products of angiosperms.

The remaining aromatic acid, 2-hydroxybenzoic acid, is not a lignin phenol. It has been found among the products synthesized by the fungus Hendersonula toruloida growing on glucose (Martin et al., 1972). The tissues of higher plants are capable of orthohydroxylation of benzoic acid to form 2-hydroxybenzoic acid. The benzoic acid may in turn be produced by $\beta$-oxidation of cinnamic acid (Towers, 1964). The bark of members of the genera Salix (willow) and Populus (poplar) contain salicin (Baumann and Pigman, 1957; Robinson, 1963), which may form 2-hydroxybenzoic acid upon oxidation and hydrolysis.

Benzenepolycarboxylic acids are detectable by the chromatographic methods employed in this study. None were found in any of the hydrolyzates. These acids are thought to result from the degradation of condensed aromatic structures. Evidently alkaline hydrolysis as used here is ineffective in breaking $\mathrm{C}-\mathrm{C}$ bonds. This result confirms those of Neyroud and Schnitzer (1975) on soil FA and HA.

Longer-chain aliphatic (fatty) acids. In most of the hydrolyzates only two components were identified as fatty acids. These were the $\mathrm{C}-16$ and $\mathrm{C}-18$ fatty acids. With the chromatographic system used for quantitative analysis of all samples in this study, resolution of saturated and unsaturated fatty acids was not possible. Thus the C-16 fatty acid peak on the chromatograms most likely represents a combination of palmitic acid and palmitoleic acid. Stearic acid, oleic acid and possibly other unsaturated C-18 acids are similarly combined in one chromatographic peak with packed SP2250 columns.

\section{Qualitative comparisons}

Compositional differences among the hydrolyzates of the sediment humic matter fractionations and the ancillary samples are best illustrated by relative abundance diagrams. All components separated by GLC are plotted relative to the most abundant component (the "base peak") in each chromatogram which is set to 100 units. These diagrams can be considered to be reconstructed gas chromatograms. Unlike the actual chromatograms, relative abundance diagrams take response factors into consideration. Thus, relative abundance diagrams are more realistic represent- ations of the composition of a hydrolyzate than are the original chromatograms.

Interpretation of relative abundance diagrams, however, must be done with caution. These diagrams do not give absolute quantitative data which can be compared on different samples. However, quantitative differences within a sample and qualitative differences between samples are shown well by these diagrams.

Ancillary samples. The ancillary samples serve to illustrate the distribution of hydrolysis components from potential source materials to the sediments. They are described first to provide a framework for the understanding of the hydrolysis data from the humic matter isolated from sediment samples.

Relative abundance diagrams for the alkaline hydrolyzates of the modern and Pleistocene spruce samples (Fig. 2) show lactic acid as the base peak in both cases. The Pleistocene spruce contains higher proportions of oxalic, vanillic and ferrulic acids. In the modern spruce hydrolyzate $\mathrm{C}-16$ and $\mathrm{C}-18$ fatty acids are higher in relative abundance.

Higher proportions of lignin components (vanillic and ferulic acids) in the Pleistocene spruce relative to the modern spruce indicate a selective preservation of lignin with respect to polysaccarides. This observation is similar to that of Hatcher et al. (1981b) who compared NMR spectra from this same Pleistocene spruce sample to those from modern spruce wood and its lignin preparations. The lack of fatty acids in the Pleistocene spruce hydrolyzate suggests their labile nature as noted by Meyers et al. (1980) in extracts of these wood samples.

Lactic, oxalic and succinic acids are the dominant components of the celery hydrolyzate (Fig. 3A). Other hydroxy acids expected from cellulose degradation are also found but in lesser proportions. The dextrose hydrolyzate (Fig. 3B) is dominated by
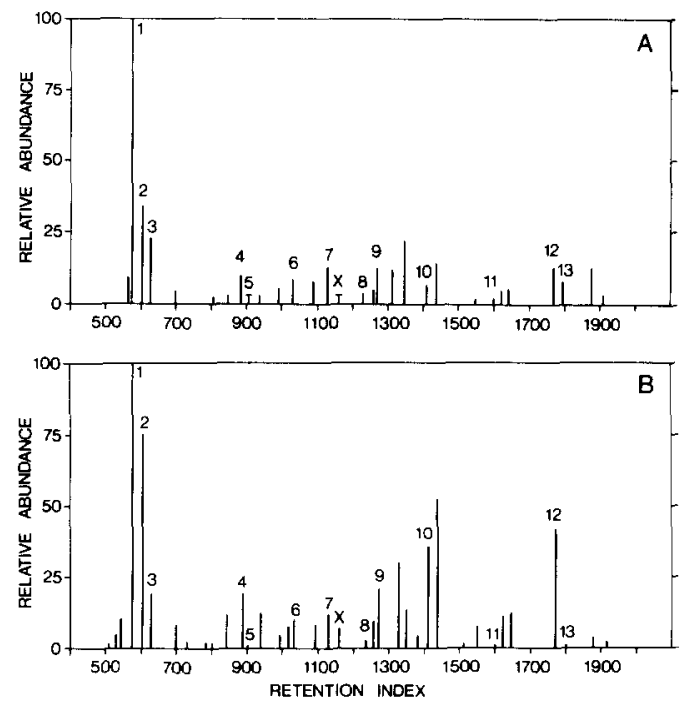

Fig. 2. Relative abundance of alkaline hydrolysis products. (A) Modern spruce; (B) Pleistocene spruce. 

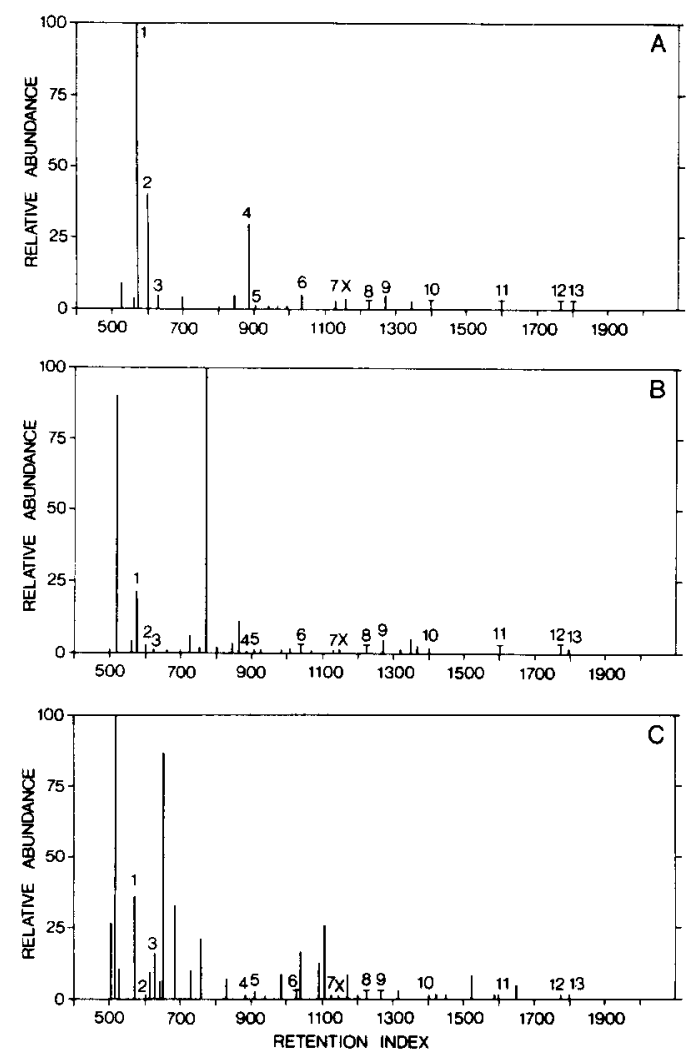

Fig. 3. Relative abundance of alkaline hydrolysis products. (A) Celery; (B) Dextrose; (C) Escherichia coli.

two unidentified components with retention indices of 522 and 771. Lesser proportions of lactic, oxalic and a few other hydroxy acids were isolated from the dextrose hydrolyzate. Differences in the composition of the celery and dextrose hydrolyzates may reflect the polymeric character of cellulose and the lack of such character in D-glucose. In cellulose the D-glucose monomers are joined by $1 \rightarrow 4, \beta$-D-glycosidic linkages. Oxidation of such 4-O-substituted D-glucose leads to products different from those of unsubstituted D-glucose (Sowden, 1957). The relative proportions of hydroxy and dicarboxylic acids in the celery hydrolyzate (Fig. 3A) resemble those of the modern spruce hydrolyzate (Fig. 2A) which is also expected to be dominated by cellulose degradation products.

Two unidentified components at retention indices of 516 and 653 dominate the hydrolysis products of E. coli (Fig. 3C). The component at 516 may be the same as a dominant component in the dextrose hydrolyzate. The only identified components in appreciable abundance in the $E$. coli hydrolyzate are lactic acid and 2-hydroxybutanoic acid. Degradation of carbohydrates could explain the origins of both of these components.

Products isolated from alkaline hydrolyzates of the freshwater diatom $A$. formosa and of the freshwater green alga Chlamydomonas $\mathrm{sp}$. are represented by relative abundance diagrams in Fig. 4. These hydrolyzates differ from each other, and they both differ significantly from the spruce, celery and dextrose samples.

Alkaline hydrolysis of $A$. formosa yields C-16 fatty acids as the base peak. Oxalic, lactic and succinic acids are also present in high relative abundances. The hydroxy acids 2-hydroxybutanoic, 3,4-dihydroxybutanoic and 2,5-dihydroxy-3-pentenoic show appreciable abundances as do 2-hydroxybenzoic acid, and C-18 fatty acids (Fig. 4A). High relative abundance of the C-16 fatty acids in the $A$. formosa hydrolyzate suggests their possible use as indicators of diatomaceous sources to the organic matter in sediments, but may be limited to young sediments (Meyers et al., 1980a).

Alkaline hydrolysis of Chlamydomonas sp. yields a number of unidentified components with retention indices between 500 and 800 . Several of these components are high in relative abundance (Fig. 4B). Rogers (1965) reported that carbohydrates in algae from two Minnesota lakes consist mostly of cellulose and hemicellulose. However, these algae also contain appreciable quantities of sugars which are not derived from cellulose. Glucose made up only about one-fifth of the carbohydrates isolated from marine phytoplankton, indicating a lower content of cellulose and hemicellulose (Degens and Mopper, 1975). It is possible that the unidentified components in Chlamydomonas sp. hydrolyzate are hydroxy acids and/or dicarboxylic acids which are degradation products of carbohydrates other than cellulose. A similar argument can be made for the high relative abundances of 2,5-dihydroxy-3-pentenoic acid and compound $X$ in this hydrolyzate.

Oxalic acid, succinic acid and 2,5-dihydroxy3-pentenoic acid are the dominant components in the hydrolyzate from the glacio-lacustrine clay and till
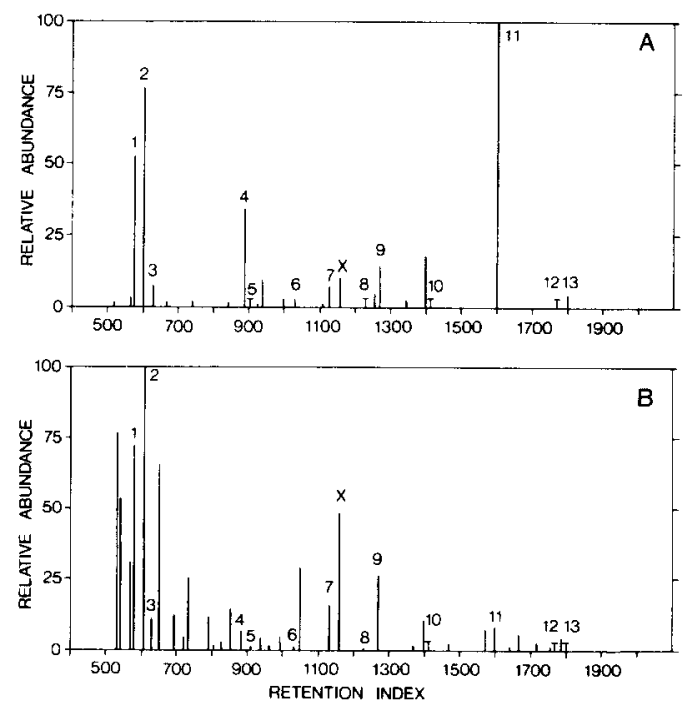

Fig. 4. Relative abundance of alkaline hydrolysis products. (A) Asterionella formosa; (B) Chlamydomonas sp. 

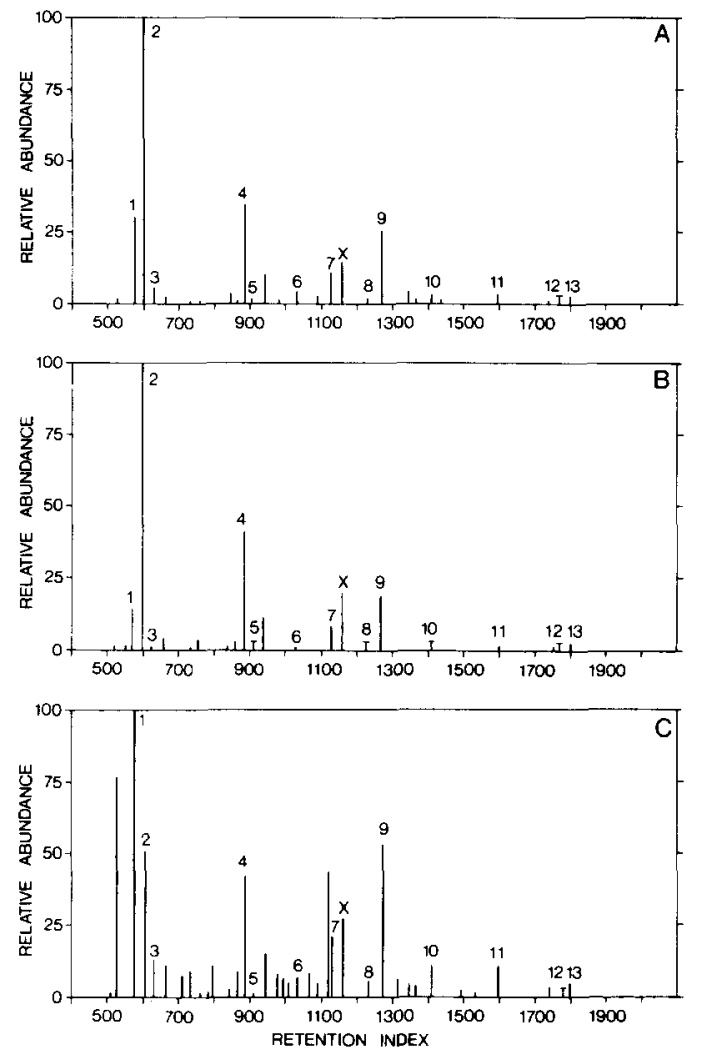

Fig. 5. Relative abundance of alkaline hydrolysis products. (A) Glaciolacustrine clay; (B) Till; (C) Topsoil.

samples (Figs 5A and 5B). Lactic acid, 2-hydroxybenzoic acid and compound $X$ are also important components in these hydrolyzates. These samples may be considered as representative of the contribution of "reworked" detrital carbon to the sediments. Compositionally, the hydrolyzates are relatively simple. This may be related to the low organic carbon content of the samples. High proportions of succinic and 2,5-dihydroxy-3-pentenoic acids relative to that of lactic acid suggest that they come from some source other than cellulose. The topsoil sample from the Lake Michigan bluff yielded a wide variety of hydrolysis products (Fig. 5C). Components representative of a number of sources have been isolated in appreciable abundance.

Sediment samples. Distribution of products released by alkaline hydrolysis of all three humic matter fractions isolated from the SLH75-18 sediment are very similar (Fig. 6). Lactic, oxalic, 2-hydroxybutanoic and succinic acids are the predominant products, suggesting that cellulose materials (cf Fig. $3 \mathrm{~A}$ ) are by far the dominant precursors to or components of fulvic acid (FA), humic acid (HA) and humin (HU) found in this Lake Huron sediment.

Humic matter fractions from the SLM77-26 sediment yield hydrolysis products as shown in Fig. 7. They are distributed somewhat differently than those from the SLH75-18 sediment. Differences in distribu- tion also occur among hydrolyzates from the FA, HA and $\mathrm{HU}$ fractions isolated from this Lake Michigan sediment. Cellulose-derived materials are indeed major components of these hydrolyzates but other precursors are also important. High relative abundances of 2,5-dihydroxy-3-pentenoic acid and compound $X$ are found in the hydrolyzates of all three fractions. As discussed previously, these may indicate a significant conribution of non-cellulosic carbohydrates to the sedimentary humic matter. The original source of such material could be algal (cf. Fig. 4B), but may also be terrigenous as the topsoil hydrolyzate also contained these compounds in significant proportions (Fig. 5C). C-16 fatty acids show a much larger relative abundance in the HA and HU fractions of the Lake Michigan sediment compared to those from Lake Huron, suggesting that diatoms (cf. Fig. 4A) contribute a relatively greater proportion of the hydrolyzable organic matter in these Lake Michigan fractions.

In a qualitative sense, humic matter fractions from the Lake Michigan sediment are more complex than those from the Lake Huron sediment. We interpret this to mean that the hydrolyzable organic matter from the Lake Michigan sediment originates from a wider variety of sources than that from the Lake Huron sediment. The proportion of cellulose precursors in the Lake Huron sedimentary humic matter is
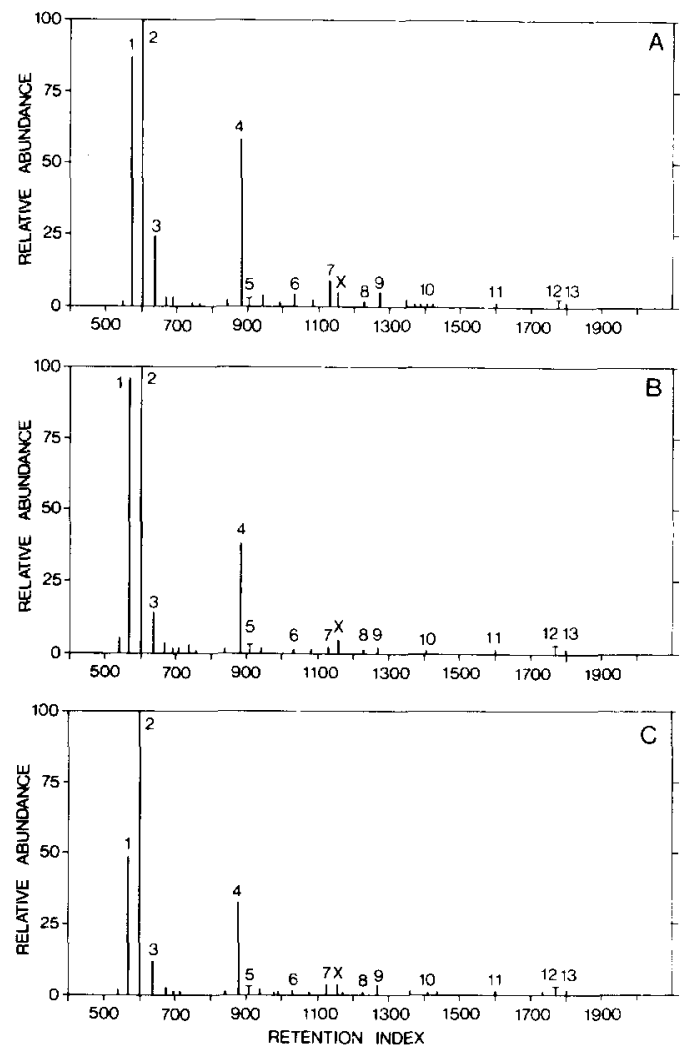

Fig. 6. Relative abundance of alkaline hydrolysis products from humic matter fractions of SLH75-18 sediment. (A) Fulvic acid; (B) Humic acid; (C) Humin. 

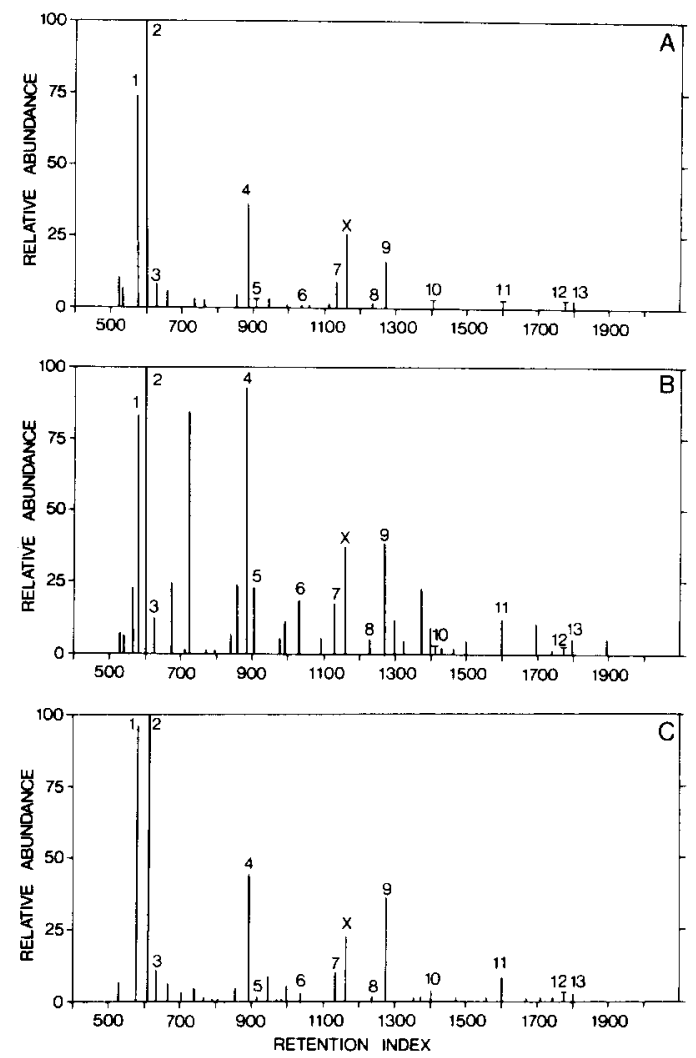

Fig. 7. Relative abundance of alkaline hydrolysis products from humic matter fractions of SLM77-26 sediment. (A) Fulvic acid; (B) Humic acid; (C) Humin.

greater relative to other sources. Humic matter from the Lake Michigan sediment probably contains degraded cellulose, suggesting that a reworked detrital component is importnat.

Along these lines it should be noted that products which should be of lignin origin (4-hydroxybenzoic, vanillic and ferrulic acids) are only minor components of all humic matter hydrolyzates from both sediments. It could be that lignin is not a significant precursor to these sedimentary humic materials, or that it is bound in a non-hydrolyzable state. The second possibility seems unlikely since all FA and HA hydrolyzates were clear solutions (HU hydrolyzates contained mineral precipitates) and lignin precursors were found in three ancillary samples, spruce and topsoil, as expected. These results agree in general with those of Meyers and Takeuchi (1979); Meyers et al. (1980a) and Leenheer (1981), who determined that lipids in sediments from nearby sites in both of these lakes are derived from both aquatic and terrestrial sources.

\section{QUANTITATIVE CONSIDERATIONS}

The previous discussion dealt with qualitative aspects of the distribution of products released by alkaline hydrolysis. The major organic source materi- als which contribute to the humic matter in these sediments may be either aquatic or terrestrial in origin. Carbohydrate derivatives and fatty acids found in the hydrolyzates suggest both sources. Lignin derivatives imply terrestrial higher plant contribution to the humic matter in these sediments. This section deals more quantitatively with hydrolysis products representative of these classes and sources.

Four of the hydrolysis products were chosen for quantitative discussion on the basis of their frequency of occurrence and uniqueness as an indicator of source. To represent polysaccharides and other carbohydrates, we chose 3,4-dihydroxybutanoic acid. This compound is found in kraft liquors and unlike some of the other aliphatic hydroxy acids and dicarboxylic acids, it is not reported to have any other biochemical source. The C-16 fatty acids were chosen to represent aquatic organic sources. C-16 fatty acids are not unique to aquatic organisms but their relative abundance is secondary to that of the C-18 acids in land plants as exemplified by the modern spruce hydrolyzate (Fig. 2A) and as discussed in Robinson (1963). Furthermore, the C-16 fatty acids peak is the "base peak" in the hydrolyzate from the diatom $A$. formosa (Fig. 4A). Diatoms dominate the phytoplankton in these lakes (Stoermer and Kopczynska, 1967; Stoermer and Yang, 1968). Two aromatic acids representing lignin sources, 4-hydroxybenzoic acid and vanillic acid, were discussed in detail previously. Yields of these compounds in the alkaline hydrolyzates are expressed in Table 4 on an equal carbon basis along with data from other workers for comparison.

\section{Comparison of sediment and ancillary samples}

Comparison of the yields of all four components for corresponding humic matter fractions from the SLH75-18 sediment and that from SLM77-26 suggests that the humic matter in the Lake Huron sediment is more labile to alkaline hydrolysis than that from the Lake Michigan sediment. The SLH75-18 hydrolyzates contained 3-37 times greater quantities of these components than did the SLM77-26 hydrolyzates. This observation probably reflects differences in the source of sediments. Modern sediments in southeastern Lake Michigan make up the Waukegan Member of the Lake Michigan formation (Lineback et al., 1980), and have as major sources fluvial contributions from rivers and shoreline erosion of glacial tills (Lineback and Gross, 1972). These modern sediments contain reworked detrital organic matter as indicated by radiocarbon ages of about $2000 \mathrm{yr}$ (King et al., 1976; Rea et al., 1980). Detrital organic matter would be more refractory to alkaline hydrolysis.

In contrast, sediment in eastern Lake Huron contains a significant component from erosion of the Silurian dolomite of the Bruce Peninsula region of Ontario as well as a glacial till component (Thomas et al., 1973). The Silurian component is relatively low 
in organic matter. Thus the Lake Huron sediment contains a higher relative proportion of newly synthesized organic matter of aquatic origin which would be more labile to alkaline hydrolysis. Simple ratios of C-16 fatty acids to 4-hydroxybenzoic acid are higher for all fractions (especially $\mathrm{HA}$ and $\mathrm{HU}$ ) of the Lake Huron sediment, showing that aquatic organic sources are indeed proportionately more important.

However, it is not only the aquatic source material that is more labile in Lake Huron sediments. The previous sedimentological arguments suggest that, as a whole, the SLM77-26 organic matter experienced long periods of subaerial exposure prior to deposition on the lake bottom. Thus the lability of the SLH75-18 humic matter suggests shorter periods of subaerial exposure. High yields of all four components in Table 4 for the Lake Huron organic matter and comparisons with the ancillary samples bear this out.

High yields of these hydrolysis products were obtained from the FA of the Prince Edward Island (PEI) podzol by Neyroud and Schnitzer (1974, 1975), who reported this soil to be poorly drained. Under poor drainage conditions one would expect preservation of labile organic matter to be greater compared to a drier soil (such as the Alberta chernozem) but possibly less than that of a subaqueous sediment. The FA and HA data (considered together) for these sediment and soil samples are consistent with this ranking of increasing degree of exposure to oxidative weathering: SLH75-18 < PEI podzol < SLM77-26 < Alberta chernozem.

Hydrolysis yields from the Lake Michigan topsoil and till samples (Table 4) indicate that they could be sources of a portion of the SLM77-26 humic matter. The topsoil yielded amounts of hydrolysis products generally in the same range as the Lake Michigan sediment, whereas the till gave very low yields consistent with its age and degree of subaerial exposure.

Glaciolacustrine clay hydrolysis yields must be explained with reference to its environment of deposition as detailed earlier, rather than simply considering its age. The presence of carbohydrates represented by the 3,4-dihydroxybutanoic acid yield can be explained by preservation due to rapid burial and isolation from oxidizing environments (unlike the Lake Michigan till). A similar argument can explain why the yields of the other three products are higher than those of the till. The difference between the glaciolacustrine clay and modern Lake Huron sediment is explained by lower aquatic productivity under periglacial conditions, little terrestrial productivity, and degradation over 10,000-11,000 yr.

Yield data from the remaining ancillary samples (Table 4) cannot be compared directly to the sediment and soil samples since they represent potential

Table 4. Yields of various components by alkaline hydrolysis and other oxidation methods ${ }^{a}$ (values are expressed as $\mu \mathrm{g} / \mathrm{mg} \mathrm{C}$ in sample)

\begin{tabular}{|c|c|c|c|c|c|}
\hline & & $\begin{array}{c}\text { 3,4-dihydroxybutanoic } \\
\text { acid }\end{array}$ & $\begin{array}{c}n-\mathrm{C} 16 \\
\text { fatty } \\
\text { acids }\end{array}$ & $\begin{array}{l}\text { 4-hydroxybenzoic } \\
\text { acid }\end{array}$ & $\begin{array}{c}\text { Vanillic } \\
\text { acid }\end{array}$ \\
\hline \multicolumn{6}{|l|}{ Alkaline hydrolysis } \\
\hline \multirow[t]{3}{*}{ SLH75-18: } & Fulvic acid & 360 & 68.8 & 157 & 81.6 \\
\hline & Humic acid & 322 & 127 & 99.8 & 149 \\
\hline & Humin & 10.6 & 48.3 & 8.1 & 39.3 \\
\hline \multirow[t]{3}{*}{ SLM77-26: } & Fulvic acid & 9.7 & 3.2 & 9.5 & Nil \\
\hline & Humic acid & 18.8 & 11.2 & 30.7 & 8.8 \\
\hline & Humin & 3.4 & 1.9 & 2.2 & Nil \\
\hline Podzol, P.E.I.: & Fulvic acid ${ }^{b}$ & NR & 82.5 & 27.3 & 62.4 \\
\hline Chernozem, Alta: & Humic acid ${ }^{b}$ & NR & 114 & 8.4 & 17.1 \\
\hline Podzol, Japan: & Humic acid ${ }^{e}$ & NR & NR & 4.2 & 1.0 \\
\hline Topsoil, Lake Michigan shore & & 5.2 & 8.2 & 4.3 & 8.4 \\
\hline Till, Lake Michigan shore & & 1.0 & 2.1 & Nil & Nil \\
\hline Glaciolacustrine clay, Lake Huron & & 10.5 & 8.0 & 4.4 & 8.1 \\
\hline White spruce, modern & & 8.3 & 2.3 & 3.7 & 6.6 \\
\hline White spruce, Pleistocene & & 7.2 & Nil & 1.8 & 24.8 \\
\hline Celery (Apium graveolens) & & 39.4 & 4.2 & 2.3 & Nil \\
\hline Phytoplankton: (A. formosa) & & 5.4 & 163 & 1.2 & Nil \\
\hline (Chlamydomonas sp.) & & Nil & 19.5 & Nil & Nil \\
\hline \multicolumn{6}{|l|}{ Alkaline $\mathrm{CuO}$ oxidation } \\
\hline Podzol, P.E.I: & Fulvic acid ${ }^{d}$ & ND & 56.0 & 15.9 & 17.3 \\
\hline Chernozem, Alta: & Humic acid ${ }^{d}$ & ND & 28.7 & 9.6 & 17.2 \\
\hline \multirow[t]{2}{*}{ Terrebonne Bay, LA: } & Sediment (No. 2) ${ }^{e}$ & ND & NR & 2.6 & 3.1 \\
\hline & Sediment (No 4) & ND & NR & 1.5 & 2.0 \\
\hline $\begin{array}{l}\text { Continental Shelf sediment, off } \mathrm{LA}^{e} \\
\text { Alkaline } \mathrm{KMnO}_{4} \text { oxidation }\end{array}$ & & $\mathrm{ND}$ & NR & 0.2 & 0.2 \\
\hline Spruce forest soil, & Fulvic acid ${ }^{f}$ & ND & ND & 11.8 & 23.9 \\
\hline \multirow[t]{2}{*}{ Norway: } & Humic acid $f$ & ND & ND & 9.1 & 19.4 \\
\hline & Humin $f$ & ND & ND & 7.3 & 17.5 \\
\hline
\end{tabular}

NR-Not reported, presence not excluded by analytical scheme.

ND-not determined, analytical conditions precluded determination.

${ }^{a}$ This work unless otherwise noted.

${ }^{b}$ Neyroud and Schnitzer (1975).

'Tsutsuki and Kuwatsuka (1979).

${ }^{d}$ Neyroud and Schnitzer (1974).

${ }^{\circ}$ Hedges and Parker (1976).

Ogner (1973). 
sources undiluted by mineral matter. Nevertheless, a few observations can be made which aid in understanding the levels of hydrolysis components obtainable from the various end numbers. The modern and Pleistocene spruce samples contained 45 and $49 \%$ TOC, respectively (Bourbonniere, 1979) Yields of 3,4-dihydroxybutanoic acid are similar for both woods, suggesting about the same lability of the cellulose in each sample. However, the yield of vanillic acid is almost four times greater for the Pleistocene spruce suggesting a selective preservation of lignin. An alternative explanation could be that the particular spruce tree contained a greater proportion of lignified tissue when it was alive $10,000 \mathrm{yr}$ ago. Fatty acids are very labile and more than $90 \%$ degraded over the 10,000 yr period of burial (Meyers et al., 1980b). This is shown again by the present alkaline hydrolysis results.

High yields of 3,4-dihydroxybutanoic acid from celery are to be expected as it is almost pure cellulose. The much higher yields from the SLH75-18 FA and HA fractions compared to celery might indicate that the sedimentary polysaccharides are partially degraded and possibly more labile to alkaline hydrolysis. Yields of C-16 fatty acids from the phytoplankton are high enough to consider these organisms as potentially significant contributors to sedimentary fatty acids. Low yields of the other components confirms that phytoplankton are not significant sources of cellulose or lignin indicators.

\section{Utility of alkaline hydrolysis}

The quantitative data in Table 4 suggests that alkaline hydrolysis as used in the present study and by Neyroud and Schnitzer (1975) is superior to the degradation schemes that cause more oxidation. Hydrolysis in the absence of oxygen evidently preserves aliphatic structures such as fatty acids. Carbohydrate moieties are broken down into smaller aliphatic components which are representative of the original structure. In contrast, carbohydrates are easily degraded to $\mathrm{CO}_{2}$ and $\mathrm{H}_{2} \mathrm{O}$ by oxidative schemes. For example, comparison of the alkaline hydrolysis results of Neyroud and Schnitzer (1975) with results of their alkaline $\mathrm{CuO}$ oxidations on the same FA and HA samples (Neyroud and Schnitzer, 1974) shows significantly higher yields by non-oxidative hydrolysis than by oxidative procedures. Aromatic components appear to be less affected by the oxidative process, confirming the utility of this procedure for specific purposes such as the phenolic aldehyde study of Hedges and Parker (1976) in their transect of Gulf of Mexico sediments.

\section{SUMMARY AND CONCLUSIONS}

Degradation by alkaline hydrolysis in the absence of oxygen preserved aliphatic and carbohydraterelated components of sediment humic matter fractions and of ancillary samples in this study. This is an advantage over other degradation methods which oxidize these components and compares well with the non-destructive NMR studies of Hatcher et al., (1980a, b, 1981 a, b). Alkaline hydrolysis has the added advantage that components may be isolated which yield information about specific organic source materials. Fatty acids of algal origin, saccharinic acids from cellulose degradation, and lignin derivatives can be determined by analysis of the hydrolyzates.

Humic matter fractions from these Lake Huron and Lake Michigan sediments contain high relative proportions of carbohydrate moieties. Evidence is also found for aquatic lipid and terrestrial lignin contributions to the organic matter of these sediments. Qualitative differences among the fulvic acid, humic acid and humin fractions from the same lake are minor, suggesting commonality of organic source materials for these fractions. Since alkaline hydrolysis in the absence of oxygen is ineffective in breaking $\mathrm{C}-\mathrm{C}$ bonds, the existence of condensed aromatic structures in the sedimentary humic matter cannot be investigated by this procedure.

Yields of hydrolysis components are related to the lability of samples. Fulvic acids are generally more labile to hydrolysis than humic acids, which are in turn more labile than humin, suggesting that yields are indicative of diagenetic stages. This in turn can be related to a sample's history of exposure to oxidative weathering and, in the case of a sediment, its environment of deposition. For instance, glaciolacustrine clay yielded significant quantities of saccharinic acids suggesting that even carbohydrates can be preserved if rapidly buried under high sedimentation rate conditions.

Acknowledgements -Financial support for parts of this study was provided by a Scott Turner Award in Earth Science administered by the Geology and Mineralogy Department, a Dissertation Grant from the Rackham School of Graduate Studies, both of the University of Michigan, and a Sigma Xi Grant-in-Aid of Research. Partial support was received from the National Science Foundation (grant EAR 7822432). We appreciate the help of N. Frew of Woods Hole Oceanographic Institution with GC-MS analyses, and thank B. J. Eadie and C. L. Schelske for use of their instruments. We thank the crews of the $R / V$ Simons and $R / V M y$ sis for their help in obtaining the cores. This study was part of the dissertation requirements of R.A.B. while at The University of Michigan.

\section{REFERENCES}

Baumann H. and Pigman W. (1957) Naturally occurring glycosides and glycosidases. In The Carbohydrates (Edited by Pigman W.), pp. 536-601. Academic Press.

Bordovskiy O. K. (1965) Accumulation and transformation of organic matter in marine sediments. Mar. Geol. 3, $1-114$.

Bourbonniere R. A. (1979) Geochemistry of humic matter in Holocene Great Lakes sediments. Ph.D. Dissertation, The University of Michigan, $373 \mathrm{pp}$.

Briggs L. H., Cambie R. C., Dan I. C., Dromgoule S. H., Fergus B. J., Ingram W. B., Lewis K. G., Small C. W., 
Thomas R. and Walker D. A. (1975) Chemistry of fungi 10. Metabolites of some fungal species. N.Z. J. Sci. $\mathbf{2 8}$, $565-576$.

Brown S. A. (1964) Lignin and tannin biosynthesis. In Biochemistry of Phenolic Compounds (Edited by Harbone J. B.), pp. 361-398. Academic Press.

Degens E. T. and Mopper K. (1975) Early diagensis of organic matter in marine soils. Soil Sci. 119, 65-72.

Dereppe J-M., Moreaux C. and Debyser Y. (1980) Investigation of marine and terrestrial humic substances by ${ }^{1} \mathrm{H}$ and ${ }^{13} \mathrm{C}$, nuclear magnetic resonance and infrared spectroscopy. Org. Geochem. 2, 117-124.

Edgington D. N. and Robbins J. A. (1975) The behaviour of plutonium and other long-lived radionuclides in Lake Michigan, II. Patterns of deposition in sediments. In Impacts of Nuclear Release into the Aquatic Environment, pp. 245-260. IAEA.

Flaig W., Beutelspacher H. and Rietz E. (1975) Chemical composition and physical properties of humic substances. In Soil Components (Edited by Giesking J. B.), Vol. 1, pp. 1-211. Springer.

Griffiths S. M. and Schnitzer M. (1975) Analytical characteristics of humic and fulvic acids extracted from tropical volcanic soils. Soil Sci. Soc. Am. Proc. 39, 861-867.

Guillard R. R. L. (1975) Culture of phytoplankton for feeding marine invertebrates. In Culture of Marine Invertebrate Animals (Edited by Smith W. L. and Chanley M. H.), pp. 29-60. Plenum Press.

Hatcher P. G., Breger I. A. and Mattingly M. A. (1980a) Structural characteristics of fulvic acids from Continental Shelf sediments. Nature 285, 560-562.

Hatcher P. G., Rowan R. and Mattingly M. A. (1980b) 'H and ${ }^{13} \mathrm{C}$ NMR of marine humic acids. Org. Geochem. 2, $77-85$.

Hatcher P. G., Breger I. A. and Earl W. L. (1981a) Nuclear magnetic resonance studies of ancient buried wood-I. Observations on the origin of coal to the brown coal stage. Org. Geochem. 3, 49-55.

Hatcher P. G., Maciel G. E. and Dennis L. W. (1981b) Aliphatic structure of humic acids; a clue to their origin. Org. Geochem. 3, 43-48.

Hedges J. I. and Parker P. L. (1976) Land-derived organic matter in surface sediments from the Gulf of Mexico. Geochim. Cosmochim. Acta 40, 1019-1029.

Hughes J. D. and Merry W. J. (1978) Marquette buried forest 9850 years old. Am Assoc. Adv. Sci. 144th Nat. Meet., Abstr., p. 115.

Ishiwatari R. (1970) Structural characteristics of humic substances in recent lake sediments. In Advances in Organic Geochemistry 1966 (Edited by Hobson G. D. and Speers G. C.), pp. 285-311. Pergamon Press.

Ishiwatari R. (1973) Chemical characterization of fractionated humic acids from lake and marine sedments. Chem. Geol. 12, 113-126.

Ishiwatari R. (1975) Chemical nature of sedimentary humic acids. In Humic Substances, Their Structure and Function in the Biosphere (Edited by Poveledo D. and Golterman H. L.), pp. 87-107. Centre for Agricultural Publishing and Documentation, The Netherlands.

Iwasiuk H., Bourbonniere R. A. and Meyers P. A. (1977) Variation of organic constituents with depth in sediment from southern Lake Huron. 20th Conf. on Great Lakes Res., IAGLR, Abstr.

Jakab T., Dubach P. Mehta N. C. and Deuel H. (1963) Abbu von huminstoffen III. Abbau mit alkali: $Z$. Pflanzenernaehr. Dueng. Bodenkd. 102, 8-17.

Kemp A. L. W. (1973) Preliminary information on the nature of organic matter in the surface sediments of Lakes Huron, Erie, and Ontario. Proc. Symp. on Hydrogeochemistry and Biogeochemistry (Edited by Ingerson E.), pp. 40-48. Clark

Kemp A. L. W. and Mudrochova A. (1973) The distribution and nature of amino acids and other nitrogen compounds in Lake Ontario surface sediment. Geochim. Cosmochim. Acta 37, 2191-2206.

King J E., Lineback J. A. and Gross D. L. (1976) Palynology and sedimentology of Holocene deposits in southern Lake Michigan. Ill. State Geol. Surv. Circ. 469, $24 \mathrm{pp}$.

Krezoski J. R., Mozley S. C. and Robbins J. A. (1978) Influence of benthic macroinvertebrates on mixing of profundal sediments in southeastern Lake Huron. Limnol. Oceanogr. 23, 1011-1016.

Leenheer M. J. (1981) Use of lipids as indicators of diagenetic and source-related changes in Holocene sediments, Ph.D. Dissertation, The University of Michigan, $246 \mathrm{pp}$.

Lineback J. A. and Gross D. L. (1972) Depositional patterns facies and trace element accumulation in the Waukegan Member of the late Pleistocene Lake Michigan formation in southern Lake Michigan. Ill. State Geol. Surv. Environ. Geol. Notes, No. 58, 25 pp.

Lineback J. A., Ayer M. J. and Gross D. L. (1970) Stratigraphy of unconsolidated sediments in the southern part of Lake Michigan. Ill. Sate Geol. Surv. Environ. Geol. Notes, No. 35, 35 pp.

Lowendahl L., Petersson G. and Samuelson O. (1975) Oxygen-alkali treatment of cellobiose. Acta Chem. Scand. B 29, 975-980.

Lowendalhl L., Petersson G. and Samuelson O. (1976) Formation of carboxylic acids by degradation of carbohydrates during kraft cooking of pine. Tappi 50, 118-121. Malinen R. and Sjostrom E. (1975) The formation of carboxylic acids from wood polysaccharides during kraft pulping. Pap. Puu 57, 728-736.

Martin J. P., Haider K. and Wolf D. (1972) Synthesis of phenols and phenolic polymers by Hendersonula toruloidea in relation to humic acid formation. Soil Sci. Soc. Am. Proc. 36, 311-315.

Meyers P. A. and Takeuchi N. (1979) Fatty acids and hydrocarbons in surficial sediments of Lake Huron. Org. Geochem. 1, 127-138.

Meyers P. A., Bourbonniere R. A. and Takeuchi N. (1980a) Hydrocarbons and fatty acids in two cores of Lake Huron sediments. Geochim. Cosmochim. Acta 44, 1215-1221.

Meyers P. A., Leenheer M. J., Erstfeld K. M. and Bourbonniere R. A. (1980b) Changes in spruce composition following burial in lake sediment for $10,000 \mathrm{yr}$. Nature 287, 534-536.

Milova N. M. (1973) Rates of production of oxalic acid by wood-destroying fungi in culture. Mikol. Fitopatol. 7, 512-514.

Muller H. M. (1975) Oxalate accumulation from citrate by Aspergillus niger I. Biosynthesis of oxalate from its ultimate precursor. Arch. Microbiol. 103, 185-189.

Muller H. M. and Frosch S. (1975) Oxalate accumulation from citrate by Aspergillus niger II. Involvement of the tricarboxylic acid cycle. Arch. Microbiol. 104, 159-162.

Neyroud J. A. and Schnitzer M. (1974) The exhaustive alkaline cupric oxide oxidation of humic acid and fulvic acid. Soil. Sci. Soc. Am. Proc. 38, 907-913.

Neyroud J. A. and Schnitzer M. (1975) The alkaline hydrolysis of humic substances. Geoderma. 13, 171-188.

Nissenbaum A. and Kaplan I. R. (1972) Chemical and isotopic evidence of the in situ origin of marine humic substances. Limnol. Oceanogr. 17, 570-582.

Nuti M. P., Brooks J. B. and Lepidi A. A. (1975) Occurrence of $\alpha-, \beta$-, and $\gamma$-hydroxybutyrates in some soil microfungi. Trans. Br. Mycol. Soc. 64, 79-87.

Ogner G. (1973) Permanganate oxidation of methylated and unmethylated fulvic acid, humic acid and humin isolated from raw humus. Acta Chem. Scand. 27, 1601-1612.

Otsuki A. and Hanya T. (1967) Some precursors of humic acid in recent lake sediment suggested by infrared spectra Geochim. Cosmochim. Acta 31, 1505-1515.

Rea D. K., Bourbonniere R. A. and Meyers P. A. (1980) 
Southern Lake Michigan sediments: Changes in accumulation rate, mineralogy and organic content. J. Gt Lakes Res. 6, 321-330.

Robbins J. A., Krezoski J. R. and Mozely S. C. (1977) Radioactivity in sediments of the Great Lakes: Postdepositional redistribution by deposit-feeding organisms. Earth Planet. Sci. Lett. 36, 325-333.

Robinson T. (1963) The Organic Constituents of Higher Plants. Burgess.

Rogers M. A. (1965) Carbohydrates in aquatic plants and associated sediments from two Minnesota lakes. Geochim. Cosmochim. Acta 29, 183-200.

Samuelson O. and Stolpe L. (1973) Degradation of cellobiitol and glucose by oxygen-alkali treatment. Acta Chem Scand. 27, 3061-3068.

Schnitzer M. and Khan S. U. (1972) Humic Substances in the Environment. Marcel Dekker.

Schubert W. J. (1965) Lignin Biochemistry. Academic Press.

Shimp N. F., Schleicher J. A., Ruch R. R., Heck D. B. and Leland H. V. (1971) Trace element and organic carbon accumulation in the most recent sediments of southern Lake Michigan. Ill. State Geol. Surv. Environ. Geol. Notes, No. 41

Sowden J. C. (1957) The saccharinic acids. In Advances in Carbohydrate Chemistry (Edited by Wolfrom M. L. and Tipson R. S.), Vol. 12, pp. 35-79. Academic Press.

Stanier R. Y., Doudoroff M. and Adelberg E. A. (1970) The Microbial World, 3rd edn. Prentice-Hall.

Stevenson F. J. (1967) Organic acids in soil. In Soil Bio- chemistry (Edited by McClaren A. D. and Peterson G. H.), Vol. 1, pp. 119-146. Marcel Dekker.

Stoermer E. F. and E. Kopczynska (1967) Phytoplankton populations in the extreme southern basin of Lake Michigan, 1962-1963: Proc. 10th Conf. on Great Lakes Research, pp. 88-106.

Stoermer E. F. and J. J. Yang (1968) A preliminary report of the fossil diatom flora from Lake Huron sediments: Proc. 1lth Conf. on Great Lakes Research, pp. 253-267. Stuermer D. H. and Payne J. R. (1976) Investigation of seawater and terrestrial humic substances with carbon- 13 and proton nuclear magnetic resonance. Geochim. Cosmochim. Acta 40, 1109-1114.

Thomas R. L., Kemp A. L. and Lewis C. F. M. (1973) The surficial sediments of Lake Huron. Can. J. Earth Sci. 10, p. 226-271.

Towers G. H. N. (1964) Metabolism of phenolics in higher plants and micro-organisms. In Biochemistry of Phenolic Compounds (Edited by Harbone J. B.), pp. 249-294. Academic Press.

Tsutsuki K. and Kuwatsuka S. (1978) Chemical studies on soil humic acids III. Nitrogen distribution in humic acids. Soil. Sci. Plant Nutr. 24, 561-570.

Tsutsuki K. and Kuwatsuka S. (1979) Chemical studies on soil humic acids V. Degradation of humic acids with potassium hydroxide. Soil Sci. Plant. Nutr. 25, 183-195.

Wershaw R. L., Mikita M. A. and Steelink C. (1981) Direct ${ }^{13} \mathrm{C}$ NMR evidence for carbohydrate moieties in fulvic acids. Environ. Sci. Technol. 15, 1461-1463. 